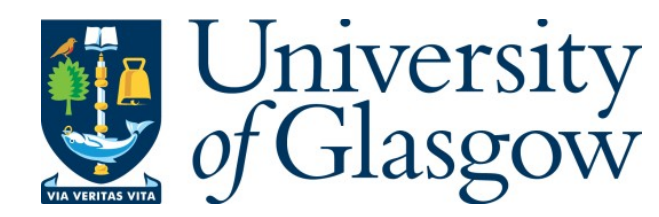

Hosseinalipour, S.M., Fattahi, A., and Karimi, N. (2016) Investigation of the transmitted noise of a combustor exit nozzle caused by burned hydrogen-

hydrocarbon gases. International Journal of Hydrogen Energy, 41(3), pp. 20752086.

There may be differences between this version and the published version. You are advised to consult the publisher's version if you wish to cite from it.

http://eprints.gla.ac.uk/114799/

Deposited on: 14 January 2016

Enlighten - Research publications by members of the University of Glasgow http://eprints.gla.ac.uk 


\title{
Investigation of the transmitted noise of a combustor exit nozzle caused by burned hydrogen-hydrocarbon gases
}

\author{
S. M. Hosseinalipour ${ }^{1 *}$, A. Fattahi ${ }^{1}$, N. Karimi $^{2}$ \\ ${ }^{1}$ School of Mechanical Engineering, Iran University of Science and Technology, Tehran, Iran \\ ${ }^{2}$ School of Engineering, University of Glasgow, Glasgow G12 8QQ, United Kingdom \\ * Corresponding author: alipour@iust.ac.ir, Tel: +982177240540
}

\begin{abstract}
Transmitted noise is a major problem in industrial and aero-engine gas turbines. One of a noise generating part in the preceding systems is exit nozzle which can play as encouraging or discouraging sound waves. The generated noise may arise from an incident acoustic wave or entropy wave. In this paper, the effect of heat transfer and inlet Mach number of the exit nozzle as well as replacing the traditional hydrocarbon fuels with hydrogen and composite of hydrogen-hydrocarbon on noise generation is studied. Further, the influence of the hydrodynamic decaying mechanisms in a nozzle on the noise generated by entropy waves is investigated. It is found that hydrogen can reduce transmitted noise in a subcritical nozzle with an acoustic incident wave or in a supercritical nozzle with an incident entropic wave.
\end{abstract}

Keywords: Transmitted noise; hydrogen-hydrocarbon composite fuel; convergent-divergent nozzle.

\section{Introduction}

Moving toward the usage of alternative fuels due to hydrocarbon sources leakage, hydrogen has been interested in previous years. Although hydrogen has been an efficient fuel in onground industries such as power plants, this has been as a working fuel in aero-engine gas turbines from about half century later. Hydrogen is currently used in propulsion of many subsonic and supersonic flight engines [1]. One of the most important benefits of hydrogen fuel is related to the environmental pollution. Hydrogen burned gases are wholly free from carbon monoxide $(\mathrm{CO})$, carbon dioxide $\left(\mathrm{CO}_{2}\right)$, sulfur oxides $\left(\mathrm{SO}_{\mathrm{x}}\right)$, unburnt hydrocarbons (UHC), and smoke. The only released emissions, however, are water and nitrogen oxides $\left(\mathrm{NO}_{\mathrm{x}}\right)$ which fall in a low level compared to the traditional fuels [2].

A major problem in combustion system, regardless the fuel used, is noise generation in the combustor exit nozzle against acoustic or entropic excitation wave [3]. Entropy waves are essentially density inhomogeneities that are produced by the unsteady combustion processes 
[4]. Entropy noises can be produced by accelerating or decelerating entropy waves in the flow [5]. They can be, for example, by passing entropy waves through a nozzle or guide vanes in the first stage of a gas turbine. The transmitted noises produce harsh environmental pollution, while, the reflection noises impact on stability of the combustion which may lead to serious operational problems and hardware damage [3]. Hence, during the last 30 years, many researches have been conducted to reveal the role of entropy and acoustic waves in the noise emission and combustion instability.

One of the first attempt to find the transmitted and reflected noise from a nozzle is belonged to Marble and Candel [6]. They found the analytical expressions for the noise produced by entropic or acoustic wave passing through a convergent-divergent nozzle. They applied the compact nozzle and Eulerian flow assumption. Their results have been a useful tool to calculate the transmitted and reflected noise up to now. Cumpsty and Marble [7] studied the noise generation in a gas turbine stage. They found that the noise was fully depended on the pressure gradient through the stage. Further, Cumpsty [8] compared the noise caused from acoustic, entropic and vorticity waves in a flow with heat release and concluded that the entropy noise was dominant. One the most solid experiments on the transmitted noise, especially entropy one, of a nozzle is the series work of Bake et al. [9,10]. They presented that the entropy noise was strongly Mach number dependent, especially at the low values.

In reality, all exit nozzles include heat transfer and hydrodynamic effects. Hydrodynamic mechanisms, such as vorticity generation and breakdown as well as interaction between flow and boundaries, can decay the entropy wave strength and thus, they can reduce the noise generation [11, 12]. Transfer of heat can also modify acoustic and entropic waves. Further, it can affect the velocity field in compressible flows and therefore leaves an indirect influence on the acoustic waves [13, 14]. It follows that these should be, therefore, involved in a realistic model of noise generation in nozzles. The problems of heat transfer in ducts have received some attentions in the literature [13-15]; in particular, Karimi et al. [13, 14] demonstrated the significant effect of mean temperature gradient upon the reflection and transmission of acoustic and entropic waves. They studied various sound sources such as, steady and unsteady heat communications.

As stated above, the influence of heat transfer on noise generation is currently obvious [13, 14] and accordingly, this should be considered in transmitted noise calculation. Further, in spite of many studies stated some of them above, one of the important keynotes partly missed in the literature is decay of the entropy waves and its relative effects on the noise generation. This can be due to whether cooling heat transfer or hydrodynamic mechanisms. Additionally, 
although some attentions have been devoted on the effect of fuel type in combustion instability [16-18] and combustion noise [19], no work has been focused on the transmitted noise rising from a burned gases of a traditional or novel composite fuel in an exit combustor nozzle; as the whole above studies applied hot air as the working fluid. These conditions, however, are really found in an exit nozzle of a combustor in industrial or aero-engine gas turbines. Thus, it follows that detection of a non-adiabatic nozzle response to entropy and acoustic waves, in the existence of hydrodynamic decaying mechanisms when an economical and clear fuel (hydrogen, for instance) is used, is central to predict the amplitude of the transmitted noises as this is seeking in the current work.

\section{Governing Equations of motion}

Before starting this section, the following assumptions should be noted.

(a) The heat sink is only radiative due to low residence time of the hot gases,

(b) cooling doesn't change the critical statues of the nozzle,

(c) there is no shock wave in the divergent part of the supercritical nozzle,

(d) there is no any friction losses,

(e) unsteady heat transfer will be negligible,

(f) the working fluid is an ideal gas with Newtonian, inviscid, non-heat-conducting characteristics. This is a mixture of the burned gases of hydrogen and hydrogen-hydrocarbon (means steam, carbon dioxide and nitrogen),

(g) the nozzle is assumed to be compact. This means the nozzle length is too small compared to the entropy and acoustic wave length.

The one-dimensional conservation equations of mass, momentum and energy are [13]

$$
\begin{gathered}
\frac{1}{\rho}\left(\frac{\partial \rho}{\partial t}+u \frac{\partial \rho}{\partial x}\right)+\frac{\partial u}{\partial x}=0 \\
\frac{\partial u}{\partial t}+u \frac{\partial u}{\partial x}+\frac{1}{\rho} \frac{\partial p}{\partial x}=0 \\
\frac{D s}{D T}=\frac{q}{\rho T} .
\end{gathered}
$$

In the above equations, $p, \rho, u, s$ and $t$ are respectively the static pressure (Pa), fluid density $\left(\mathrm{kg} / \mathrm{m}^{3}\right)$, velocity $(\mathrm{m} / \mathrm{s})$, entropy $(\mathrm{kJ} / \mathrm{kgK})$ and time $(\mathrm{s})$. Further, $\mathrm{T}$ is the fluid absolute temperature and $\mathrm{q}$ is the heat addition or loss per unit volume. 
Flow variables are then substituted by the summation of the steady and perturbation parts such that $\mathrm{g}=\overline{\mathrm{g}}+\mathrm{g}^{\prime}$ in which $\mathrm{g}$ is a flow property. The following analysis will be on the basis of linear method. The linear methods have received many attentions due to its validity to predict combustion instabilities in a wide range when they combined in low order models [3]. The linear analysis has its comparable benefits, such as simplicity and accuracy in many engineering cases. Ignoring the second order terms results in the linearized form of mass, momentum and energy equations of (1)- (3). These are

$$
\begin{gathered}
\left(\frac{\partial}{\partial \mathrm{t}}+\overline{\mathrm{u}} \frac{\partial}{\partial \mathrm{x}}\right) \frac{\rho}{\bar{\rho}}+\overline{\mathrm{u}} \frac{\partial}{\partial \mathrm{x}}\left(\frac{\hat{\mathrm{u}}}{\overline{\mathrm{u}}}\right)=0, \\
\frac{\partial}{\partial \mathrm{t}}\left(\frac{\mathrm{u}}{\overline{\mathrm{u}}}\right)+\overline{\mathrm{u}} \frac{\partial}{\partial \mathrm{x}}\left(\frac{\mathrm{u}}{\overline{\mathrm{u}}}\right)+\frac{\rho}{\bar{\rho}} \frac{\partial \overline{\mathrm{u}}}{\partial \mathrm{x}}+2 \bar{\rho} \overline{\mathrm{u}} \frac{\mathrm{u}}{\overline{\mathrm{u}}} \frac{\partial \overline{\mathrm{u}}}{\partial \mathrm{x}}+\overline{\mathrm{p}} \frac{\partial}{\partial \mathrm{x}}\left(\frac{\hat{p}}{\overline{\mathrm{p}}}\right)+\frac{\dot{p}}{\overline{\mathrm{p}}} \frac{\partial \dot{\mathrm{p}}}{\partial \overline{\mathrm{p}}}=0, \\
\frac{D s^{\prime}}{\mathrm{Dt}}=\frac{\overline{\mathrm{q}} \mathrm{R}}{\overline{\mathrm{p}}}\left(\frac{\mathrm{q}^{\prime}}{\overline{\mathrm{q}}}-\frac{\mathrm{u}^{\prime}}{\overline{\mathrm{u}}}-\frac{\mathrm{p}^{\prime}}{\overline{\mathrm{p}}}\right) .
\end{gathered}
$$

It, further, follows from the first law of thermodynamics that

$$
\frac{\dot{s}}{c_{p}}=\frac{\dot{p}}{\gamma p}+\frac{\dot{\rho}}{\rho} \text {. }
$$

Combining Eqs. (4), (6) and (7) yields

$$
\left(\frac{\partial}{\partial \mathrm{t}}+\overline{\mathrm{u}} \frac{\partial}{\partial \mathrm{x}}\right)\left(\frac{\dot{\mathrm{p}}}{\gamma \overline{\mathrm{p}}}\right)+\overline{\mathrm{u}} \frac{\partial}{\partial \mathrm{x}}\left(\frac{\mathrm{u}^{\prime}}{\overline{\mathrm{u}}}\right)=\frac{\overline{\mathrm{q} R}}{\overline{\mathrm{p}}}\left(\frac{\mathrm{q}^{\prime}}{\overline{\mathrm{q}}}-\frac{\mathrm{u}^{\prime}}{\overline{\mathrm{u}}}-\frac{\mathrm{p}^{\prime}}{\overline{\mathrm{p}}}\right) .
$$

The acoustic waves are assumed to be planar propagating waves in both directions of the onedimensional domain. Thus,

$$
\begin{aligned}
& \frac{p^{\prime}}{\gamma \bar{p}}=P^{+} \exp \left(i \omega\left[t-\frac{x}{\bar{u}+c}\right]\right)+P^{-} \exp \left(i \omega\left[t-\frac{x}{\bar{u}-c}\right]\right), \\
& \frac{u^{\prime}}{c}=U^{+} \exp \left(i \omega\left[t-\frac{x}{\bar{u}+c}\right]\right)+U^{-} \exp \left(i \omega\left[t-\frac{x}{\bar{u}-c}\right]\right),
\end{aligned}
$$

in which $\omega$ is the angular frequency and the superscript + and - respectively denote downstream-travelling and upstream-travelling waves. Further, the convected entropy wave can be presented as

$$
\frac{s^{\prime}}{c_{p}}=\sigma \exp \left[i \omega\left(t-\frac{x}{u}\right)\right] .
$$


By substitution of the harmonic solutions for the pressure and velocity into Eq. (4) and (8), the following expressions can be developed.

$$
\begin{gathered}
\rho^{+}=\mathrm{U}^{+}, \\
\rho^{-}=-\mathrm{U}^{-}, \\
\mathrm{U}^{+}=\mathrm{P}^{+}, \\
\mathrm{U}^{-}=-\mathrm{P}^{-}, \\
\mathrm{q}^{+}=\mathrm{P}^{+}\left(\gamma+\frac{1}{\mathrm{M}}\right)+\mathrm{P}^{-}\left(\gamma-\frac{1}{\mathrm{M}}\right) .
\end{gathered}
$$

Due to the fixed geometry of the nozzle, the mass variation at the inlet and outlet are identical. Hence,

$$
\frac{1}{M}\left(\frac{u}{c}\right)+\frac{\rho^{\prime}}{\bar{\rho}}=\text { const. }
$$

Because of the heat transfer effects on the entropy waves, an energy balance should be introduced. This is

$$
\dot{q}=\dot{m} C_{p}\left(T_{t 2}-T_{t 1}\right),
$$

where $\mathrm{T}_{\mathrm{t}}, \dot{\mathrm{m}}$ and $\dot{\mathrm{q}}$ are the stagnation temperature, mass flow rate and heat transfer rate, respectively. Linearizing Eq. (14) and considering $\left(\frac{\dot{\mathfrak{m}}}{\overline{\dot{m}}}\right)_{1}=\left(\frac{\dot{\mathfrak{m}}}{\overline{\dot{m}}}\right)_{2}$ [20] for the two parts of the nozzle reveals that

$$
\frac{\hat{T}_{t 1}}{\bar{T}_{t 1}}+\frac{\dot{q}}{\overline{\dot{m}} C_{p} \bar{T}_{t 1}}=\frac{\hat{T}_{t 2}}{\bar{T}_{t 2}}\left(1+\frac{1}{B}\right)+\frac{1}{B} \frac{\dot{m}}{\dot{\bar{m}}}
$$

As mentioned before, $\mathrm{q}$ is the heat transfer per unit volume and

$$
q=\frac{\dot{m}}{V} C_{p} \Delta T_{t}=\frac{\rho_{1} u_{1}}{\frac{V}{A}} C_{p} \Delta T_{t}
$$

By linearizing Eq. (16), the heat transfer fluctuation can be expressed as

$$
\frac{q \prime}{\bar{q}}=A \frac{T t^{\prime} 2}{\bar{T}_{t 2}}-B \frac{T^{\prime} t 1}{\bar{T}_{t 1}}+\frac{\rho_{1}}{\bar{\rho}_{1}}+\frac{u_{1}^{\prime}}{\bar{u}_{1}}
$$

in which

$$
A=-\frac{\bar{T}_{t 2}}{\bar{T}_{t 2}-\bar{T}_{t 1}}
$$




$$
B=-\frac{\bar{T}_{t 1}}{\bar{T}_{t 2}-\bar{T}_{t 1}}
$$

The stagnation temperature is defined as

$$
\mathrm{T}_{\mathrm{t}}=\mathrm{T}\left(1+\frac{\gamma-1}{2} \mathrm{M}^{2}\right)
$$

Linearization of this relation yields

$$
\begin{aligned}
& \frac{\stackrel{\mathrm{T}}{\mathrm{t}}_{\mathrm{T}}}{\overline{\mathrm{T}}_{\mathrm{t}}}=\frac{1}{1+\frac{1}{2}(\gamma-1) \mathrm{M}^{2}}\left[\gamma\left(\frac{\mathrm{p}^{\prime}}{\gamma \overline{\mathrm{p}}}\right)-\frac{\dot{\rho}}{\rho}+(\gamma-1) \frac{\mathrm{Mu}}{\mathrm{c}}\right]= \\
& \frac{1}{1+\frac{1}{2}(\gamma-1) \mathrm{M}^{2}}\left[(\gamma-1)\left(\frac{\mathrm{p}^{\prime}}{\gamma \overline{\mathrm{p}}}\right)-\frac{\dot{s}}{\mathrm{c}_{\mathrm{p}}}+(\gamma-1) \frac{\mathrm{Mu}}{\mathrm{c}}\right] .
\end{aligned}
$$

Further, the cross sectional variation in a choked nozzle is associated with [20]

$$
\frac{\mathrm{A}}{\mathrm{A}^{*}}=\frac{1}{\mathrm{M}}\left(\frac{2}{\gamma+1}\left(1+\frac{1}{2}(\gamma-1) \mathrm{M}^{2}\right)\right)^{\frac{\gamma+1}{2(\gamma-1)}} \exp \left[\left(-\frac{\Delta s}{\mathrm{R}}\right)\left(1-\frac{\mathrm{T}}{\mathrm{T}_{\mathrm{t}}}\right)\right]
$$

where $\mathrm{A}^{*}$ is the throat surface area and $\Delta \mathrm{s}$ is the entropy change. Through linearization of this equation and considering constant temperature through each part of the nozzle $(\Delta s=0)$, it can be readily shown that $\frac{\mathrm{M}}{\mathrm{M}}=0$ [20]. This implies that

$$
\frac{\underline{u}}{c}-\frac{\gamma}{2} M\left(\frac{\dot{p}}{\gamma p}\right)+\frac{1}{2} M \frac{\dot{\rho}}{\rho}=0 .
$$

For a choked nozzle without any shock waves, the following relation holds [6]

$$
\mathrm{P}_{1}^{+}+\mathrm{P}_{1}^{-}-\mathrm{P}_{2}^{+}-\mathrm{P}_{2}^{-}=0 \text {. }
$$

Heat transfer modifies the Mach number at the outlet of a conduit with a constant cross section [21]. However, the variation of Mach number through a heat transferring conduit with variable area section (e.g. a nozzle) differs from that of a constant area conduit traditionally presented by Rayleigh line [22]. Considering the nozzle geometry, inlet condition and the variation of the stagnation temperature, outlet Mach number can be found by an iterative method [22].

\section{Dispersion and dissipation of the entropy waves}

As mentioned in the introduction, detection of the decay mechanisms of the entropy waves is a crucial keynote missed in the literature. The effect of preceding annihilation mechanisms on 
entropy wave strength, which include hydrodynamic mechanisms and heat transfer, is theoretically considered here by details. The change in the entropy wave then varies the noise generated by the wave.

\subsection{Hydrodynamic mechanisms}

A number of hydrodynamic effects such as vorticity generation and flow and boundaries interactions may disturb the flow and cause the decay of entropy waves [23, 24]. These are highly complicated and problem dependent phenomena. In the current investigation, the net effect of these is represented by a decay coefficient $\left(\mathrm{k}_{\mathrm{n}}\right)$ for the entropy wave attenuation. Thus,

$$
\frac{\sigma_{2}}{\sigma_{1}}=1-\mathrm{k}_{\mathrm{n}}
$$

where $\sigma_{2}$ and $\sigma_{1}$ respectively denote the amplitude of the entropy wave $\left(\sigma=\frac{\dot{s}}{\mathrm{c}_{\mathrm{p}}}\right)$ in the downstream and upstream sections of the nozzle throat. $\mathrm{k}_{\mathrm{n}}$ depends on the nozzle geometry and fluid flow and should be exclusively determined for each nozzle and flow condition. Considering Eqs. (7), (13), (15) and assuming an adiabatic- i.e. $\overline{\mathrm{T}}_{\mathrm{t} 1}=\overline{\mathrm{T}}_{\mathrm{t} 2}$-compact nozzle in cooperating Eq. (23), the response of a subcritical nozzle to a dissipative incident entropy wave is expressed by

$$
\begin{aligned}
& P_{1}^{-}=\left(\frac{-M_{1} M_{2} k_{n}\left(1+\frac{1}{2}(\gamma-1) M_{1}^{2}\right)+\frac{M_{1}}{2}\left(M_{1}^{2}\left(1-k_{n}\right)-M_{2}^{2}-\frac{2 k_{n}}{\gamma-1}\right)}{\left(1-M_{1}\right)\left[M_{1}\left(1+\frac{1}{2}(\gamma-1) M_{2}^{2}\right)+M_{2}\left(1+\frac{1}{2}(\gamma-1) M_{1}^{2}\right)\right]}\right) \sigma, \\
& P_{2}^{+}=\frac{M_{2}}{M_{2}+1}\left(\frac{-M_{1} k_{n}\left(1+\frac{1}{2}(\gamma-1) M_{2}^{2}\right)+\frac{M_{1}^{2}}{2}\left(1-k_{n}\right)-\frac{M_{2}^{2}}{2}-\frac{k_{n}}{\gamma-1}}{M_{1}\left(1+\frac{1}{2}(\gamma-1) M_{2}^{2}\right)+M_{2}\left(1+\frac{1}{2}(\gamma-1) M_{1}^{2}\right)}\right) \sigma .
\end{aligned}
$$

It should be noted that the $\mathrm{P}_{1}^{+}$and $\mathrm{P}_{2}^{-}$are wholly assumed to be zero in the subcritical condition. It is because of neglecting the entering acoustic wave at the inlet and prevention of penetrating the acoustic response wave through divergent to convergent part, respectively. Combining Eqs. (7), (21), (22) and (23), and assuming compactness, the acoustic response of a supercritical nozzle to a dissipative entropy wave is expressed by

$$
\begin{aligned}
& P_{2}^{-}=\frac{1}{4}\left(\frac{\left.-M_{1}+\frac{k_{n}}{2}(\gamma-1) M_{1} M_{2}-M_{2}\left(1-k_{n}\right)\right)}{1+\frac{1}{2}(\gamma-1) M_{1}}\right) \sigma, \\
& P_{2}^{+}=\frac{1}{4}\left(\frac{-\frac{k_{n}}{2}(\gamma-1) M_{2} M_{1}+M_{2}\left(1-k_{n}\right)-M_{1}}{1+\frac{1}{2}(\gamma-1) M_{1}}\right) \sigma,
\end{aligned}
$$


and, the reflected component takes the same form as that derived by Marble and Candel [6],

$$
P_{1}^{-}=\frac{-\frac{M_{1}}{2}}{1+\frac{1}{2}(\gamma-1) M_{1}} \sigma \text {. }
$$

\subsection{Heat transfer}

Heat transfer can leave a decaying effect on the incident entropy wave. The entropy wave may lose part of its thermal energy as it radiates heat to the surroundings. Once again, it is assumed that an entropy wave is incident upon a subcritical nozzle. As explained earlier, in such configuration $\mathrm{P}_{1}^{+}=\mathrm{P}_{2}^{-}=0$. Setting $\sigma_{1}=\sigma$ and manipulating Eqs. (7), (15) and (19), for a subcritical nozzle reveals

$$
\begin{gathered}
\frac{1}{1+\frac{1}{2}(\gamma-1) M_{1}{ }^{2}}\left[(\gamma-1)\left(1-M_{1}\right) P_{1}^{-}+\sigma\right]+\frac{\dot{Q}}{\overline{\dot{m}} C_{p} \bar{T}_{t 1}}+ \\
{\left[-\left(1+\frac{1}{B}\right) \frac{1}{1+\frac{1}{2}(\gamma-1) M_{2}{ }^{2}}(\gamma-1)\left(1+M_{2}\right)-\frac{1}{B}\left(\frac{1}{M_{2}}+1\right) P_{2}^{+}=\sigma_{2}\left(\frac{1-\frac{B^{-1}}{2}(\gamma-1) M_{2}{ }^{2}}{\frac{1}{1+\frac{1}{2}(\gamma-1) M_{2}{ }^{2}}}\right) .\right.}
\end{gathered}
$$

By applying Eq. (13) to the upstream and downstream sections of the nozzle and assuming zero unsteady heat transfer, a relation among the amplitudes of the transmission and reflection acoustic waves and that of the entropy wave is derived. This is

$$
P_{2}^{+}=\frac{M_{2}\left(M_{1}-1\right)}{M_{1}\left(M_{2}+1\right)} P_{1}^{-}-\frac{M_{2}}{M_{2}+1} \sigma+\frac{M_{2}}{M_{2}+1} \sigma_{2} .
$$

Substituting Eq. (30) into (29), results in

$$
\frac{K_{p 1}}{K_{s u b c, \sigma 2}} P_{1}^{-}+\frac{K_{s u b c, \sigma}}{K_{s u b c, \sigma 2}} \sigma=\sigma_{2},
$$

where

$$
\begin{gathered}
K_{P 1}=\frac{1}{1+\frac{1}{2}(\gamma-1) M_{1}^{2}}(\gamma-1)\left(1-M_{1}\right)-\left(1+\frac{1}{B}\right) \frac{1}{1+\frac{1}{2}(\gamma-1) M_{2}^{2}}(\gamma-1) \frac{M_{2}\left(M_{1}-1\right)}{M_{1}}-\frac{1}{B} \frac{\left(M_{1}-1\right)}{M_{1}}, \\
K_{s u b c, \sigma}=\frac{1}{1+\frac{1}{2}(\gamma-1) M_{1}{ }^{2}}+\left(1+\frac{1}{B}\right) \frac{1}{1+\frac{1}{2}(\gamma-1) M_{2}{ }^{2}}(\gamma-1) M_{2}+\frac{1}{B^{\prime}} \\
K_{s u b c, \sigma 2}=\frac{\left(1+B^{-1}\right)\left((\gamma-1) M_{2}+1\right)}{1+\frac{1}{2}(\gamma-1) M_{2}{ }^{2}} .
\end{gathered}
$$

In Eqs. (31-c) and (31-d), subscript "subc" denotes subcritical status. 
Due to the smaller length and flow residence time of the upstream part compared to those in the downstream section, it is assumed that heat transfer has a negligible effect on the convergent part. Considering this assumption, the reflected entropic wave is expressed by

$$
P_{1}^{-}=-\left(\frac{M_{2}-M_{1}}{1-M_{1}}\right)\left[\frac{\frac{1}{2} M_{1} \sigma}{1+\frac{1}{2}(\gamma-1) M_{1} M_{2}}\right] \text {. }
$$

The ratio of transmission and incident entropy waves is defined as

$$
\frac{\sigma_{2}}{\sigma}=\frac{K_{p 1}}{K_{\text {sub }, \sigma 2}}\left(\frac{M_{1}-M_{2}}{1-M_{1}}\right)\left[\frac{\frac{1}{2} M_{1}}{1+\frac{1}{2}(\gamma-1) M_{1} M_{2}}\right]+\frac{K_{\sigma}}{K_{s u b, \sigma 2}} .
$$

By substituting this ratio into $\mathrm{k}_{\mathrm{n}}=1-\frac{\sigma_{2}}{\sigma}$ and Eq. (25), one can readily find the amplitude of the transmitted wave.

In the supercritical case, $\mathrm{P}_{1}^{-}, \mathrm{P}_{2}^{+}$and $\mathrm{P}_{2}^{-}$should be considered. By assuming negligible heat transfer effect on the upstream section of the nozzle, the reflected entropy wave becomes the same as Eq. (28). Using Eq. (7),

$$
\rho_{2}^{+}=P_{2}^{+}-\sigma_{2} .
$$

Eq. (18) then provides the transmission wave,

$$
P_{2}^{+}=P_{2}^{-}\left(\frac{1+\frac{1}{2}(\gamma-1) M_{2}}{1-\frac{1}{2}(\gamma-1) M_{2}}\right)+\frac{\sigma_{2}}{2}\left(\frac{M_{2}}{1-\frac{1}{2}(\gamma-1) M_{2}}\right) .
$$

By using Eq. (22) and after some algebraic manipulation, it can be shown that

$$
P_{2}^{+}=-\frac{M_{1}}{4}\left(\frac{1+\frac{1}{2}(\gamma-1) M_{2}}{1+\frac{1}{2}(\gamma-1) M_{2}}\right) \sigma+\frac{M_{2}}{4} \sigma_{2} .
$$

Combining Eqs. (15) and (22) yields the following

$$
\begin{gathered}
\left(\frac{1+\frac{1}{2}(\gamma-1) M_{2}^{2}}{1-\frac{B^{-1}}{2}(\gamma-1) M_{2}^{2}}\right)\left(\frac{1}{1+\frac{1}{2}(\gamma-1) M_{1}^{2}}(\gamma-1)\left(1-M_{1}\right)-\frac{1}{1+\frac{1}{2}(\gamma-1) M_{2}^{2}}\left(1+B^{-1}\right)(\gamma-1)\left(1-M_{2}\right)-\right. \\
\left.B^{-1}\left(1-\frac{1}{M_{2}}\right)\right) P_{1}^{-}+\frac{1}{1+\frac{1}{2}(\gamma-1) M_{1}^{2}}\left(\frac{1+\frac{1}{2}(\gamma-1) M_{2}^{2}}{1-\frac{B^{-1}}{2}(\gamma-1) M_{2}^{2}}\right) \sigma-\left(\frac{1+\frac{1}{2}(\gamma-1) M_{2}^{2}}{1-\frac{B^{-1}}{2}(\gamma-1) M_{2}^{2}}\right)\left(\frac{2 M_{2}(\gamma-1)\left(1+B^{-1}\right)}{1+\frac{1}{2}(\gamma-1) M_{2}{ }^{2}}+\right. \\
\left.\frac{2 B^{-1}}{M_{2}}\right) P_{2}^{+}=\sigma_{2}-\frac{\dot{Q}}{\overline{\dot{m}} C_{p} \bar{T}_{t 1}}\left(\frac{1+\frac{1}{2}(\gamma-1) M_{2}{ }^{2}}{1-\frac{B^{-1}}{2}(\gamma-1) M_{2}^{2}}\right)
\end{gathered}
$$

Considering Eqs. (22), (28), (36) and (37), the ratio of the incident and transmitted entropy waves becomes 


$$
\frac{\sigma_{2}}{\sigma}=\frac{K_{s u p c, \sigma}}{K_{s u p c, \sigma 2}}
$$

where

$$
\begin{gathered}
K_{\text {sup } c, \sigma}=\left(\frac{1+\frac{1}{2}(\gamma-1) M_{2}{ }^{2}}{1-\frac{B^{-1}}{2}(\gamma-1) M_{2}^{2}}\right)\left(\frac { - \frac { M _ { 1 } } { 2 } } { 1 + \frac { 1 } { 2 } ( \gamma - 1 ) M _ { 1 } } \left(\frac{(\gamma-1)\left(1-M_{1}\right)}{1+\frac{1}{2}(\gamma-1) M_{1}{ }^{2}}-\frac{\left(1+B^{-1}\right)(\gamma-1)\left(1-M_{2}\right)}{1+\frac{1}{2}(\gamma-1) M_{2}{ }^{2}}-\right.\right. \\
\left.\left.B^{-1}\left(1-\frac{1}{M_{2}}\right)\right)+\frac{1}{1+\frac{1}{2}(\gamma-1) M_{1}{ }^{2}}\right)+\left(\frac{1+\frac{1}{2}(\gamma-1) M_{2}^{2}}{1-\frac{B^{-1}}{2}(\gamma-1) M_{2}^{2}}\right)\left(\frac{2 M_{2}(\gamma-1)\left(1+B^{-1}\right)}{1+\frac{1}{2}(\gamma-1) M_{2}{ }^{2}}+2 B^{-1}\right) \\
K_{\text {sup }, \sigma 2}=1+\frac{M_{2}}{4}\left(\frac{1+\frac{1}{2}(\gamma-1) M_{2}{ }^{2}}{1-\frac{B^{-1}}{2}(\gamma-1) M_{2}{ }^{2}}\right)\left(\frac{2 M_{2}(\gamma-1)\left(1+B^{-1}\right)}{1+\frac{1}{2}(\gamma-1) M_{2}{ }^{2}}+\frac{2 B^{-1}}{M_{2}}\right)
\end{gathered}
$$

and subscript "supc" stands for the supercritical condition. $\mathrm{P}_{2}^{+}$and $\mathrm{P}_{2}^{-}$are obtained by Eqs. (26) and (27). Further, $\mathrm{P}_{1}^{-}$is found through Eq. (22).

Here, the response of heat transferring nozzle to an incident acoustic wave by the strength of $\mathrm{P}_{1}^{+}=\varepsilon$ is further analysed. Considering Eqs. (12) and (13), in the subcritical regime, a relation among the transmitted acoustic wave in the diverging part and the acoustic components in the converging section is derived. This is

$$
P_{2}^{+}=\frac{1}{M_{1}\left(1+M_{2}\right)}\left[M_{2}\left(P_{1}^{+}-P_{1}^{-}\right)+M_{1} M_{2}\left(P_{1}^{+}+P_{1}^{-}\right)\right] \text {. }
$$

As stated earlier, in this subcritical nozzle, $\mathrm{P}_{2}{ }^{-}$is assumed to be zero. Combining Eqs. (12), (17) and (19) gives

$$
P_{1}^{-}=\frac{K_{1}^{+}}{K_{1}{ }^{-}} \varepsilon
$$

where

$$
\begin{aligned}
& {K_{1}}^{+}=-B\left(1+\frac{1}{2}(\gamma-1){M_{2}}^{2}\right)(\gamma-1)\left(1+M_{1}\right)+A\left(1+\frac{1}{2}(\gamma-1) M_{1}^{2}\right)(\gamma- \\
& \text { 1) }\left(\frac{M_{2}}{M_{1}}+M_{2}\right)+\left(1+\frac{1}{2}(\gamma-1){M_{1}}^{2}\right)\left(1+\frac{1}{2}(\gamma-1){M_{2}}^{2}\right)\left(\frac{-\left(\gamma M_{2}+1\right)}{M_{1}\left(1+M_{2}\right)}-\frac{\left(\gamma M_{2}+1\right)}{\left(1+M_{2}\right)}+\right. \\
& (\gamma-1)), \\
& {K_{1}}^{-}=B\left(1+\frac{1}{2}(\gamma-1) M_{2}^{2}\right)(\gamma-1)\left(1-M_{1}\right)+A\left(1+\frac{1}{2}(\gamma-1) M_{1}^{2}\right)(\gamma-1)\left(\frac{M_{2}}{M_{1}}-\right. \\
& \left.M_{2}\right)+\left(1+\frac{1}{2}(\gamma-1) M_{1}{ }^{2}\right)\left(1+\frac{1}{2}(\gamma-1) M_{2}^{2}\right)\left(\frac{\left(\gamma M_{2}+1\right)}{\left(1+M_{2}\right)}-\frac{\left(\gamma M_{2}+1\right)}{M_{1}\left(1+M_{2}\right)}+(\gamma-1)\right) .
\end{aligned}
$$

The transmitted acoustic wave in the downstream section is found by substituting Eq. (40-a) into Eq. (39) which gives 


$$
P_{2}^{+}=\frac{1}{M_{1}\left(1+M_{2}\right)}\left[M_{2} \varepsilon\left(1-\frac{K_{1}^{+}}{K_{1}{ }^{+}}\right)+M_{1} M_{2} \varepsilon\left(1+\frac{K_{1}^{+}}{K_{1}}\right)\right]
$$

In the supercritical regime, relations derived by Marble and Candel [6] are still valid. These are

$$
\begin{aligned}
& P_{1}^{-}=\frac{1-\frac{1}{2}(\gamma-1) M_{1}}{1+\frac{1}{2}(\gamma-1) M_{1}} \varepsilon, \\
& P_{2}^{+}=\frac{1+\frac{1}{2}(\gamma-1) M_{2}}{1+\frac{1}{2}(\gamma-1) M_{1}} \varepsilon, \\
& P_{2}^{-}=\frac{1-\frac{1}{2}(\gamma-1) M_{2}}{1+\frac{1}{2}(\gamma-1) M_{1}} \varepsilon .
\end{aligned}
$$

However, the outlet Mach number should be now calculated by Eq. (23) which involves heat transfer effect.

\section{Burning chemical reaction of the fuels}

Complete combustion of pure methane and hydrogen are

$$
\begin{gathered}
\mathrm{CH}_{4}+\mathrm{O}_{2}+3.76 \mathrm{~N}_{2} \rightarrow \mathrm{CO}_{2}+2 \mathrm{H}_{2} \mathrm{O}+3.76 \mathrm{~N}_{2}, \\
2 \mathrm{H}_{2}+\mathrm{O}_{2}+3.76 \mathrm{~N}_{2} \rightarrow 2 \mathrm{H}_{2} \mathrm{O}+3.76 \mathrm{~N}_{2} .
\end{gathered}
$$

The composite fuel is chosen by the equal mole fraction of hydrogen and methane. Thus, its complete combustion is

$$
\mathrm{CH}_{4}+\mathrm{H}_{2}+2.5\left(\mathrm{O}_{2}+3.76 \mathrm{~N}_{2}\right) \rightarrow \mathrm{CO}_{2}+32 \mathrm{H}_{2} \mathrm{O}+9.4 \mathrm{~N}_{2} \text {. }
$$

The specific heat coefficient and heat capacity for the working fluid (the mixture of $\mathrm{CO}_{2}, \mathrm{H}_{2} \mathrm{O}$ and $\mathrm{N}_{2}$ ) are calculated in consideration with their mole fractions using Dalton model [25].

\section{Validation}

To validate the relations, three following points are targeted.

(1) When the variation of the stagnation temperature tends to zero (flow becomes adiabatic), the value of A and B in Eq. (17) approaches infinity. Under this condition, Eqs. (24) to (27), (30), (31), (36), (39) and (40-a) reduce to those of Marble and Candel [6]. Moreover, setting the decay of entropy waves to zero, Eqs. (33) and (38) tend to unity, which means $\sigma_{2}=\sigma_{1}$, 
(2) Karimi et al. $[13,14]$ calculated the acoustic energy of reflection $\left(\Sigma_{R}\right)$ and transmission $\left(\Sigma_{\mathrm{T}}\right)$ coefficient in a duct with a mean temperature gradient. In their setting, the incident wave was entropic $(\sigma)$, and they defined acoustic energy reflection and transmission coefficients as

$$
\Sigma_{\mathrm{R}}=\frac{(\gamma-1)\left(1-\overline{\mathrm{M}}_{0}\right)^{2}}{\bar{\rho}_{0}{ }^{2} \overline{\mathrm{M}}_{0} \overline{\mathrm{c}}_{0}{ }^{4}}\left|\frac{\mathrm{R}}{\sigma}\right|^{2}, \Sigma_{\mathrm{T}}=\frac{(\gamma-1)\left(1+\overline{\mathrm{M}}_{1}\right)^{2}}{\bar{\rho}_{0} \bar{\rho}_{1} \overline{\mathrm{M}}_{0} \overline{\mathrm{c}}_{0} \overline{\mathrm{c}}_{1}}\left|\frac{\mathrm{T}}{\sigma}\right|^{2},
$$

where $\mathrm{R}$ and $\mathrm{T}$ are the reflected and transmitted components of the acoustic wave $[13,14]$. Under compact conditions, these coefficients are calculated by the current relations and compared by the low frequency simulation of Karimi et al. [13], in which $\frac{T_{t 2}}{T_{t 1}}=0.5$. Fig. 1 depicts this comparison, which clearly shows a good agreement.

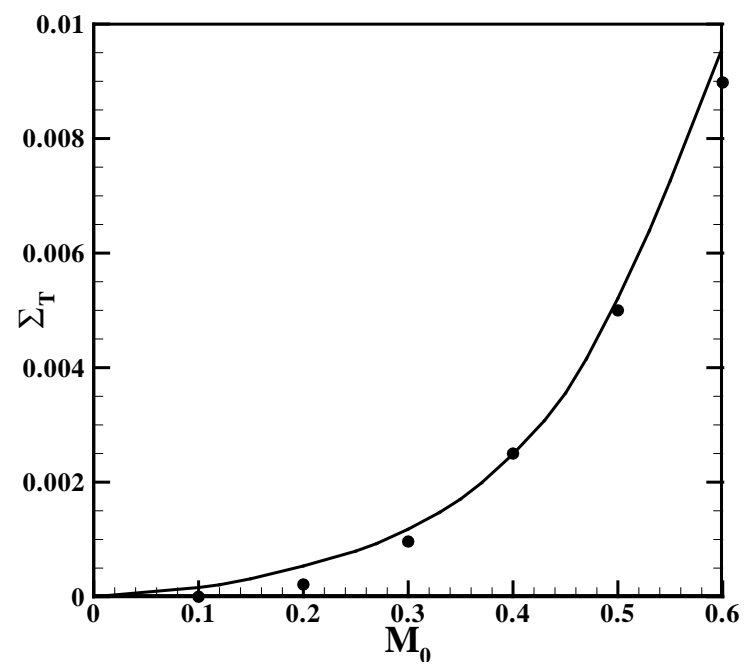

(a)

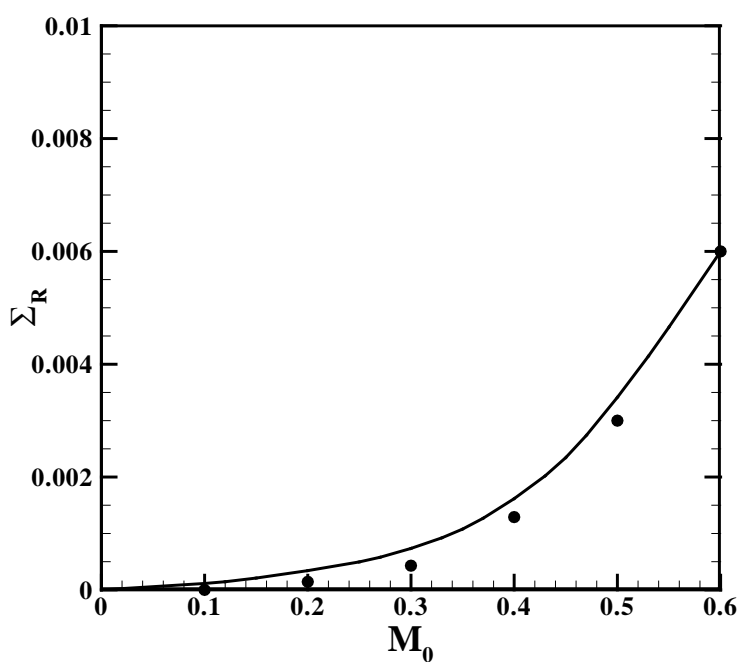

(b)

Fig.1. The reflected (a) and transmitted acoustic energy (b) to the incident entropic wave: the current relations (solid lines) and numerical simulation of Karimi et al. [13] (circle symbols)

The deviation may be arisen from non-zero frequency in [13] because of features of their computer code in comparison with the current compact results with zero frequency,

(3) Karimi et al. $[13,14]$ agreed that in a one-dimensional, adiabatic duct flow and in the absence of entropy wave, the sum of acoustic reflected and transmission is unity. They expressed this summation as

$$
\Sigma_{R}+\Sigma_{T}=\frac{\left(1-\bar{M}_{0}\right)^{2}}{\left(1+\bar{M}_{0}\right)^{2}}\left|\frac{R}{I}\right|^{2}+\frac{\bar{\rho}_{0} \bar{c}_{0}\left(1+\bar{M}_{l}\right)^{2}}{\bar{\rho}_{l} \bar{c}_{l}\left(1+\bar{M}_{0}\right)^{2}}\left|\frac{T}{I}\right|^{2}
$$

where the first and second terms are the reflected and transmitted energy.

\section{Results and Discussions}

\subsection{The nozzle geometry}


The area change affects quasi-one-dimensional relations of a nozzle. In the current study, a nozzle with a convergent length smaller ten times than the divergent length is considered. The area ratio are chosen in such a way that the outlet Mach numbers do not change in a constant heat transfer condition for the selected inlet Mach numbers [20], as Table 1 shows.

Table 1- The various inlet and outlet Mach numbers and area ratios of the nozzle studied [20]

\begin{tabular}{|c|c|c|c|}
\hline \multicolumn{2}{|c|}{} & The unchoked condition & The choked condition \\
\cline { 3 - 4 } \multicolumn{2}{|c|}{} & $M_{2}=0.4$ & $M_{2}=1.2$ \\
\hline \multirow{2}{*}{$M_{1}=0.025$} & $A_{1} / A^{*}$ & 14.604 & 23.365 \\
\cline { 2 - 4 } & $A_{2} / A^{*}$ & 1.000 & 1.032 \\
\hline \multirow{2}{*}{$M_{1}=0.05$} & $A_{1} / A^{*}$ & 7.310 & 11.695 \\
\cline { 2 - 4 } & $A_{2} / A^{*}$ & 1.000 & 1.032 \\
\hline \multirow{2}{*}{$M_{1}=0.1$} & $A_{1} / A^{*}$ & 3.671 & 5.873 \\
\cline { 2 - 4 } & $A_{2} / A^{*}$ & 1.000 & 1.032 \\
\hline
\end{tabular}

\subsection{Nozzle response with an acoustic incident wave}

The transmitted $\left(\mathrm{P}_{2}^{+}\right)$of the nozzle response with an incident acoustic wave is presented in Fig. 2 in subcritical condition versus the stagnation temperature ratio at the outlet to the inlet $(\theta)$. The incident acoustic wave may produce by the turbulence dependent phenomena or the interaction of the turbulence with the flame. As can be seen, the response waves rise at lower inlet nozzle Mach number. This increases up to 18 and 30 percent for transmitted and reflected waves, respectively, when the inlet Mach number reduces from 0.1 to 0.025 . The important issue observed in Fig. 2 is that the burned gas of the hydrogen fuel generates a lower transmitted noise level compared to the other fuels, especially when the burned gases are cooled. For instance, this can reduce up to 25 percent transmitted noise in the inlet Mach number of 0.025 at $\theta=0.9$. All trends of subcritical condition in Fig. 2 show a counterpoint near the adiabatic condition.
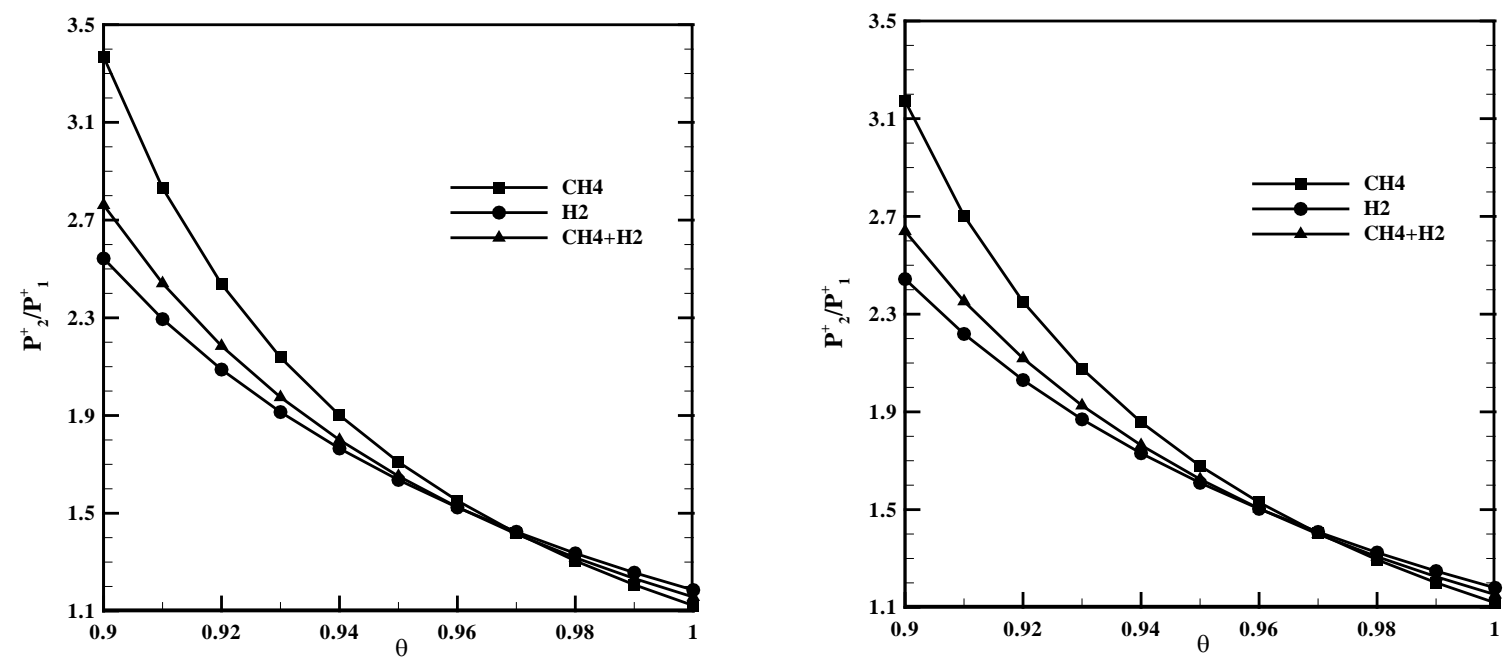
(a)

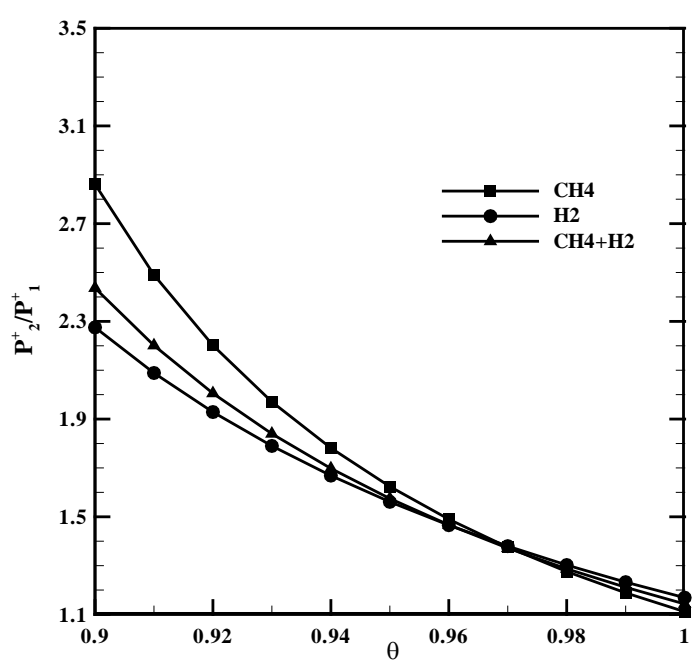

(c) (b)

Fig. 2. The transmitted $\left(\mathrm{P}_{2}^{+}\right)$wave versus $\theta$ for a supercritical nozzle and the inlet Mach number of (a) 0.025, (b) 0.05, (c) 0.1 .

The inverse trend of transmitted noise seen in subcritical condition is found in supercritical nozzle, as Fig. 3 shows. The transmitted noise is increased by using hydrogen fuel. This may increase about 8 percent in transmitted noise from the exit nozzle. Similar to the subcritical condition, $\mathrm{P}_{2}^{+}$noise is increased by decreasing inlet nozzle Mach number and $\theta$ (increasing cooling). Mitigating inlet Mach number from 0.1 to 0.025 can increase the transmitted noise of supercritical nozzle up to 15 percent.

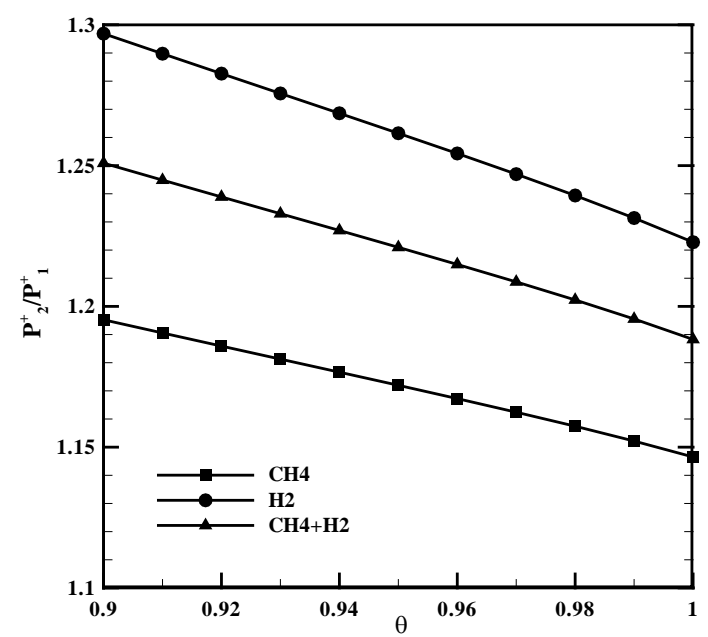

(a)

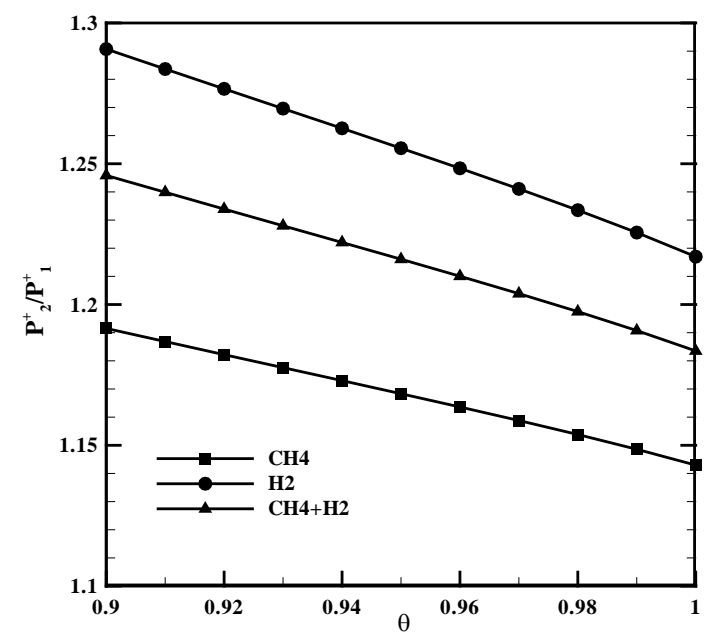

(b) 


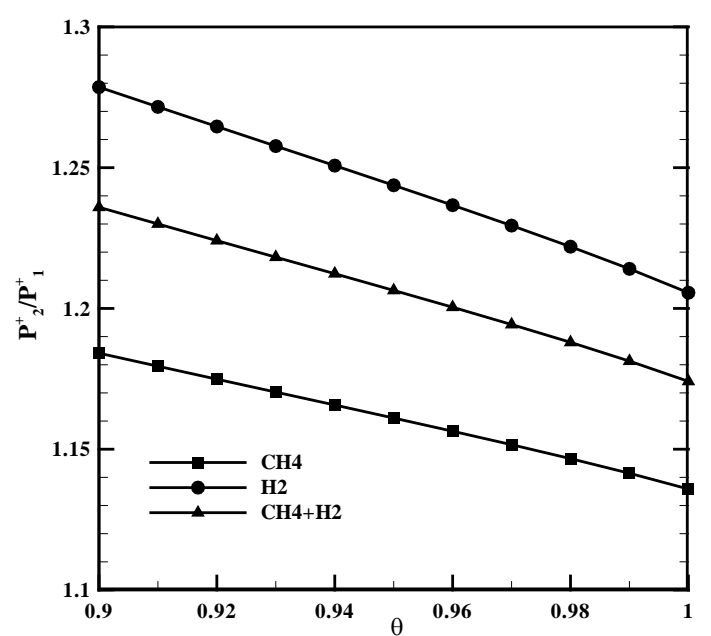

(c)

Fig. 3. The transmitted $\left(\mathrm{P}_{2}^{+}\right)$wave versus $\theta$ for a supercritical nozzle and the inlet Mach number of (a) 0.025 , (b) 0.05 , (c) 0.1 .

\subsection{Nozzle response with an entropic incident wave}

The transmitted noise versus $\theta$ for various inlet nozzle Mach numbers with an entropic incident wave in subcritical condition is presented in Fig. 4. The variation is independent of burned fuel. Similar to the acoustic excitation, the transmitted noise intensifies at lower inlet Mach numbers, but, the values of noise, is too smaller compared to the noise generated by the entropic waves. Fig. 4 also shows the ratio of the entropy wave at the outlet to the inlet in a subcritical nozzle. So small variation is found by changing fuel which somewhat highlights at the lowest $\theta$ studied here. Further, the ratio is mitigated by intensifying cooling; this is the reason of such behavior in the transmitted noise. The variation of the ratio, however, can be deemed negligible by changing the inlet nozzle Mach number. As a result, modifications related to changing the Mach number in transmitted noise presented in Fig. 4 arise from the effect of velocity variations on the produced noise not on the entropy waves.
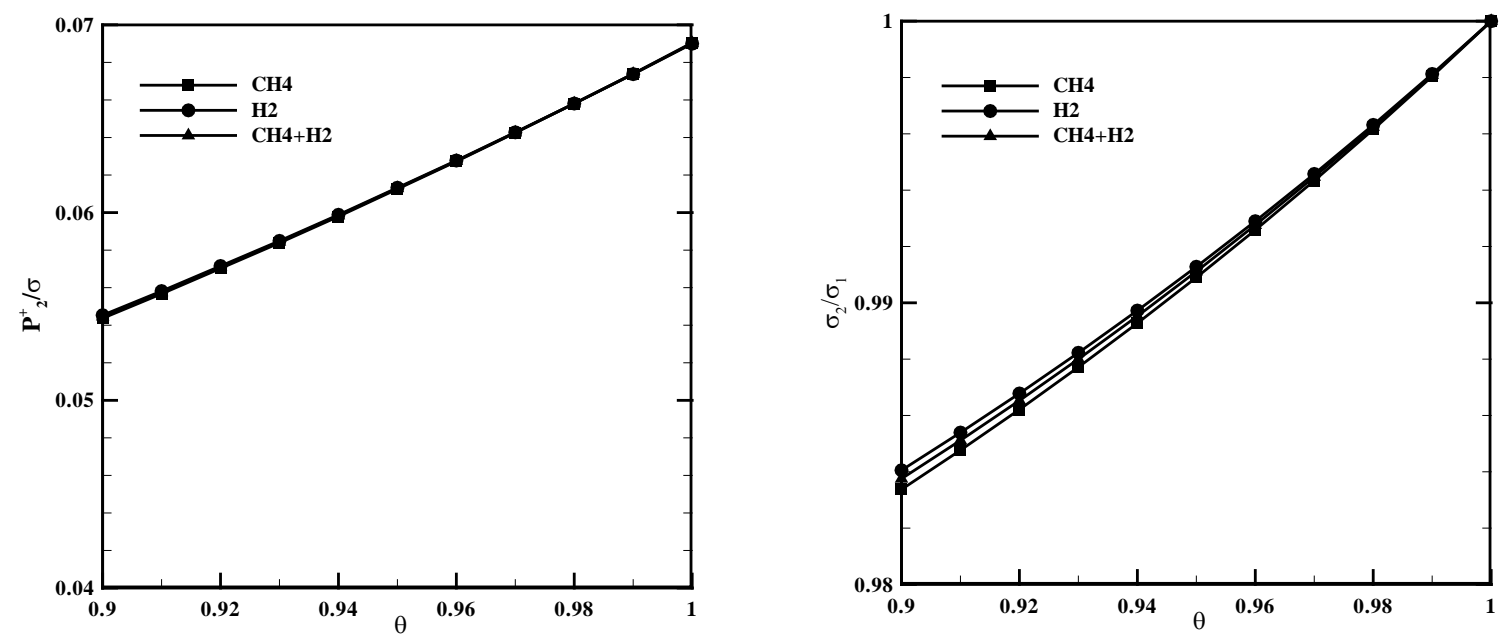

(a) 

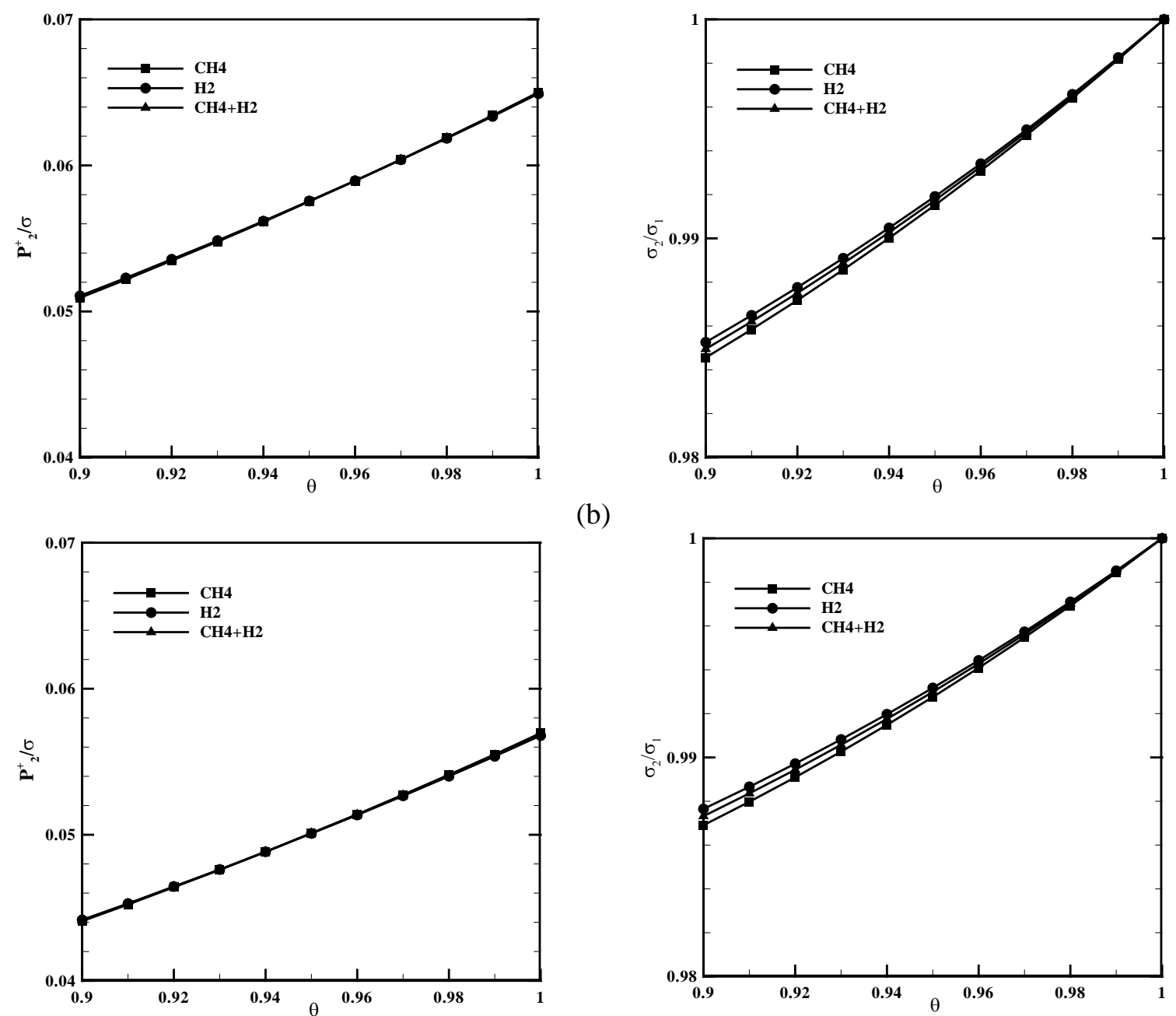

(b)

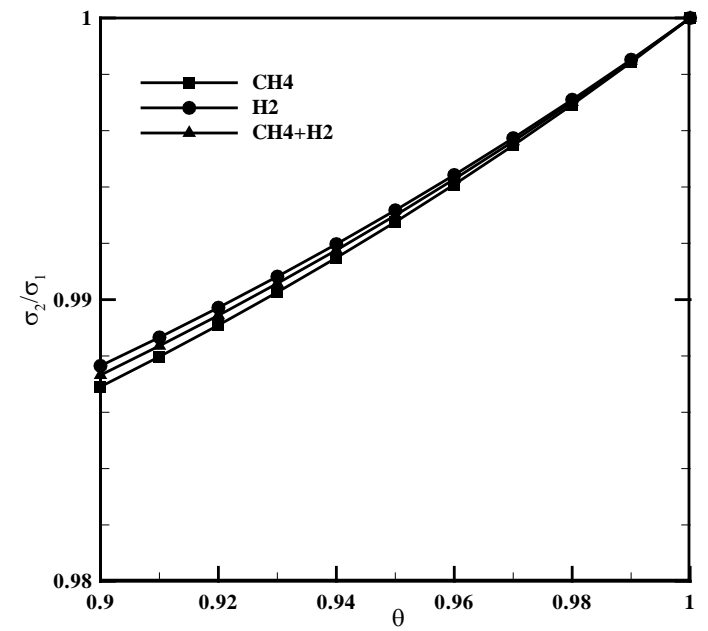

(c)

Fig. 4. The transmitted $\left(\mathrm{P}_{2}^{+}\right)$wave and the ratio of the entropy wave at the outlet to the inlet $\left(\sigma_{2} / \sigma_{1}\right)$ versus $\theta$ for a subcritical nozzle and the inlet Mach number of (a) 0.025 , (b) 0.05 , (c) 0.1 .

Fig. 5 depicts the effect of hydrodynamic decaying mechanisms on the transmitted noise in an adiabatic and subcritical nozzle. Indeed, these decaying mechanisms (presented by $\mathrm{k}_{\mathrm{n}}$ ) affect directly the entropy waves amplitude and then, the noise is modified. Due to low residence time of the fluid in the nozzle, low values of the annihilation factor $(\mathrm{kn}<0.1)$ are chosen. Fig. 5 shows that only 10 percent decrease in the entropy wave strength can reduce the transmitted noise up to 100 percent. Although the noise generated by the entropy wave is not serious, these results illustrate that intensification of decaying mechanisms of entropy waves, even low values, can reduce the noise considerably. As observed, fuel changing remains no effect on the nozzle response by variation hydrodynamics decaying mechanisms. 


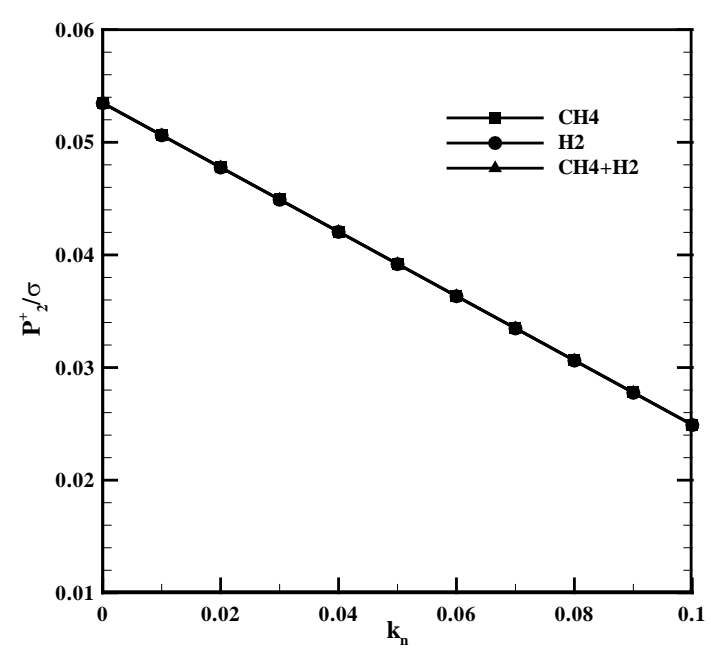

(a)

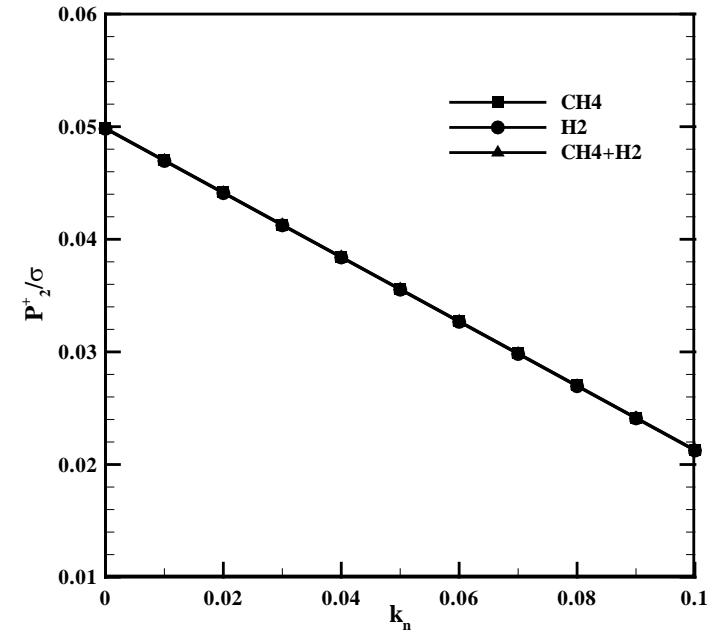

(b)

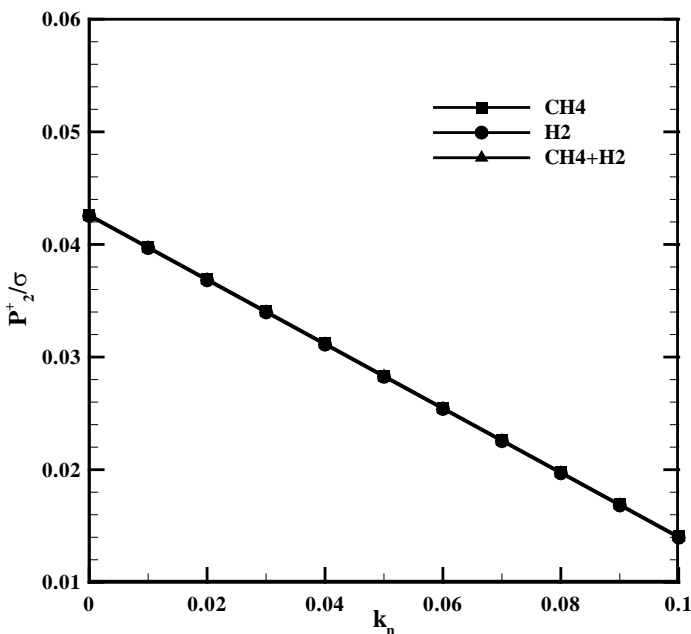

(c)

Fig. 5. The transmitted $\left(\mathrm{P}_{2}^{+}\right)$wave versus $\mathrm{k}_{\mathrm{n}}$ for a subcritical nozzle and the inlet Mach number of (a) 0.025, (b) 0.05, (c) 0.1.

Fig. 6 demonstrates the transmitted noise of entropy wave versus $\theta$ in supercritical condition. On the contrary of the subcritical condition, the transmitted noise increases by increasing cooling. Further, the value of noise is more considerable compared to the subcritical condition. By increasing inlet nozzle Mach number, the transmitted noise decreases and, the effect of fuel change, further, become more obvious. Changing fuel, however, remains negligible effect on the generated noise. Fig. 6 also shows the ratio of the entropy wave at the outlet to the inlet in a supercritical nozzle. Surprisingly, this ratio depicts the inverse trend by increasing cooling compared to the transmitted noise. This shows that although the entropy wave strength decreases by decreasing $\theta$, the transmitted wave increases due to the effect of the cooling as a sound source [13]. 

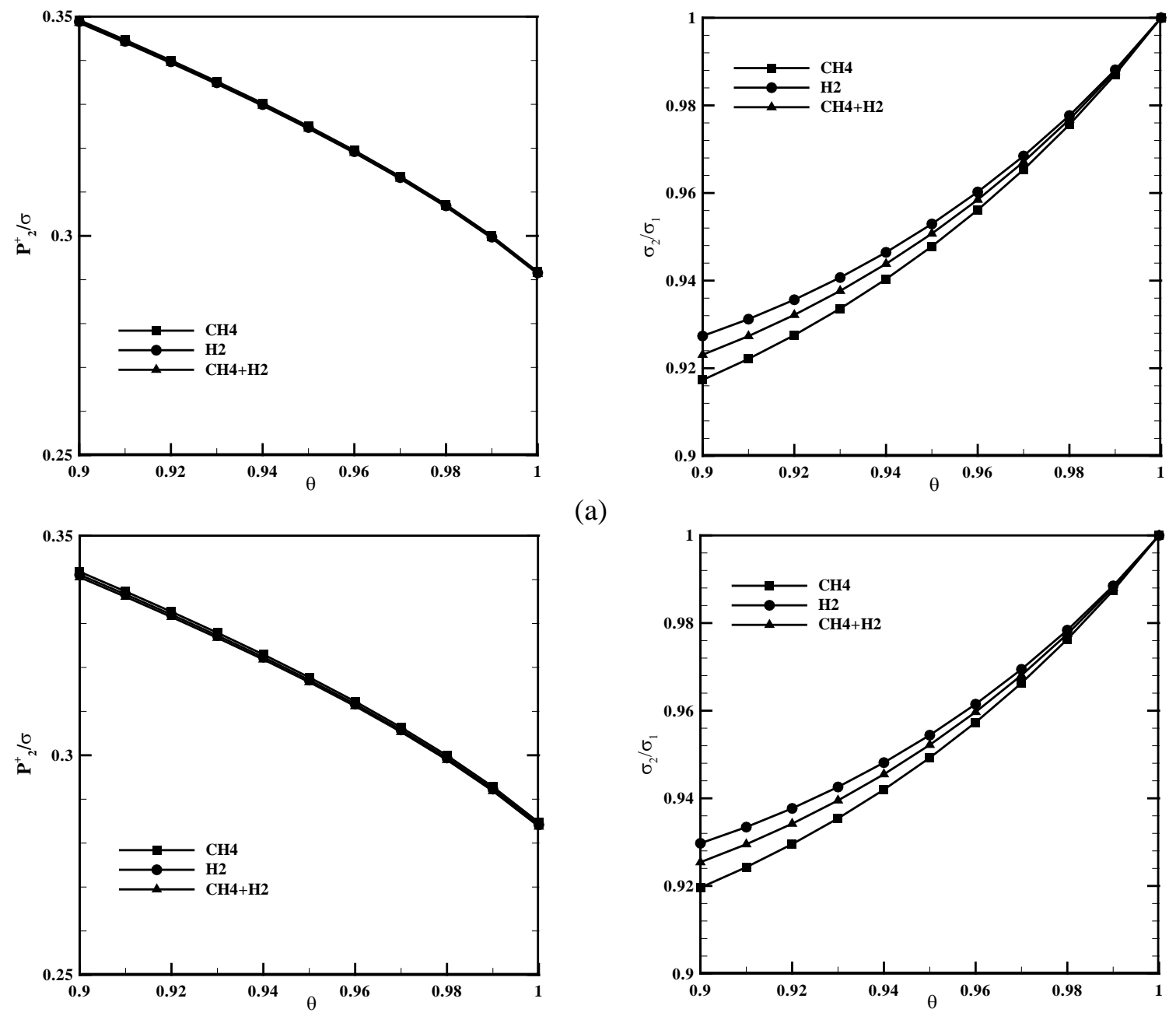

(a)
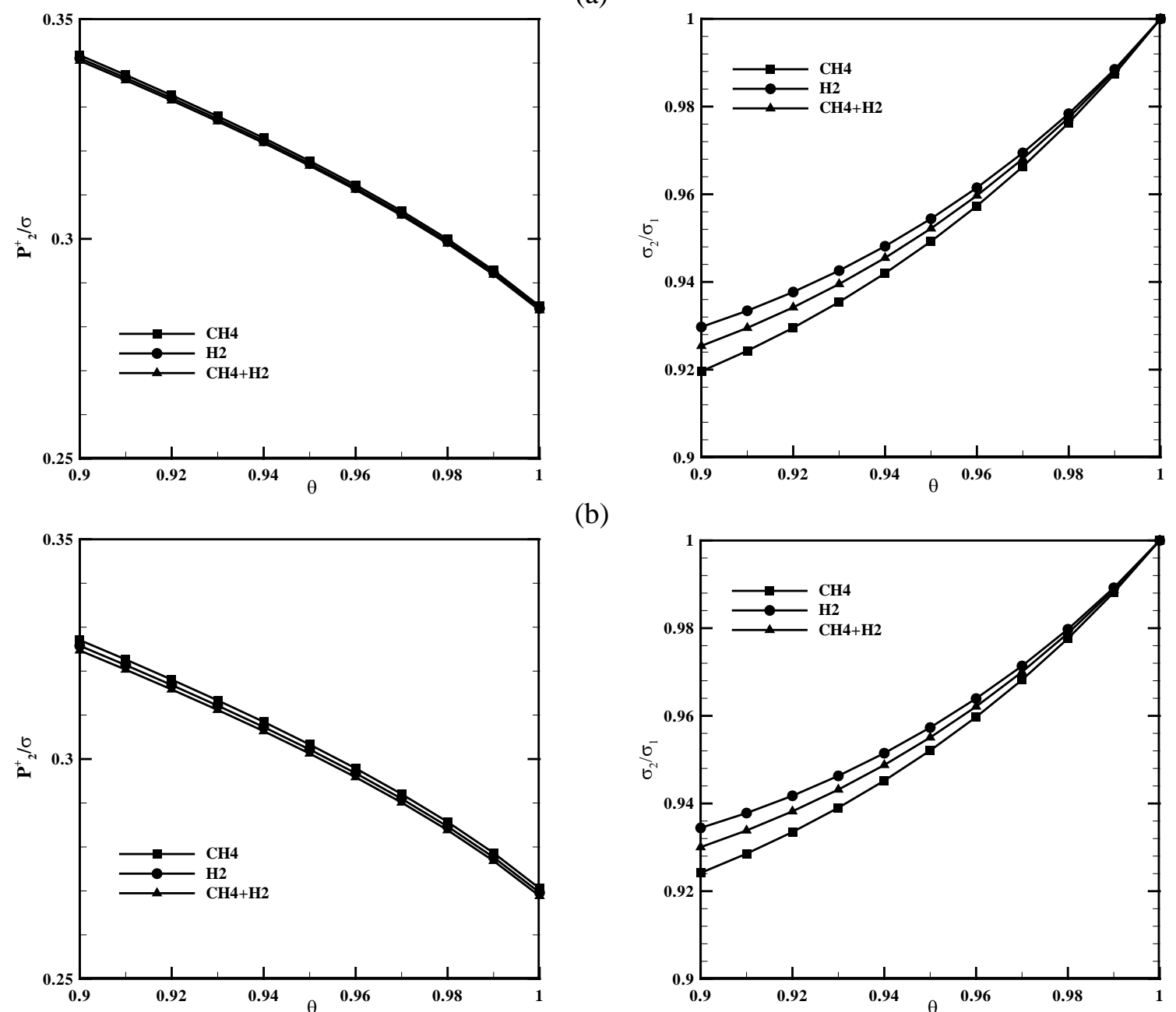

(b)

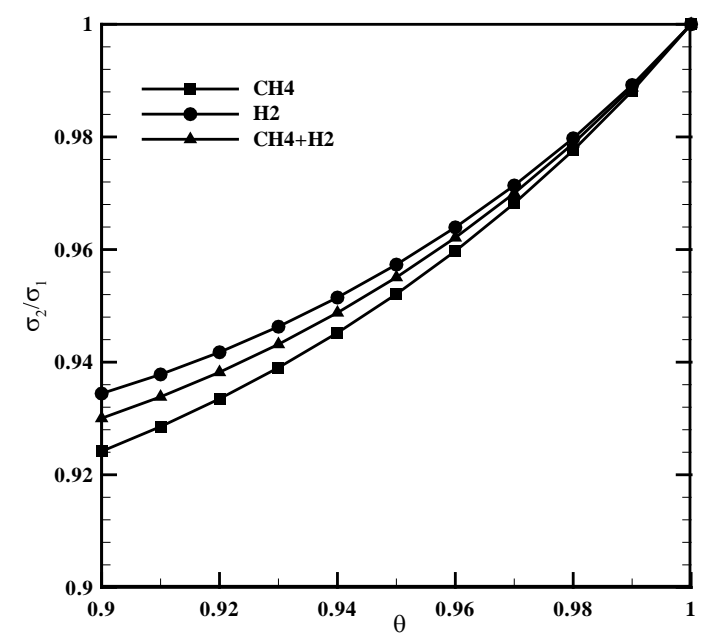

(c)

Fig. 6. The transmitted $\left(\mathrm{P}_{2}^{+}\right)$wave and the ratio of the entropy wave at the outlet to the inlet $\left(\sigma_{2} / \sigma_{1}\right)$ versus $\theta$ for a supercritical nozzle and the inlet Mach number of (a) 0.025, (b) 0.05, (c) 0.1.

Fig. 7 shows the transmitted noise versus the hydrodynamic decaying effect $\left(\mathrm{k}_{\mathrm{n}}\right)$ for supercritical condition. By increasing the inlet Mach number nozzle, the transmitted noise is decreased and the effect of changing fuel becomes somewhat obvious. Reducing 10 percent 
in the strength of entropy wave by hydrodynamic mechanisms can mitigate slightly more than this reduction in the transmitted noise at the Mach number of 0.1.

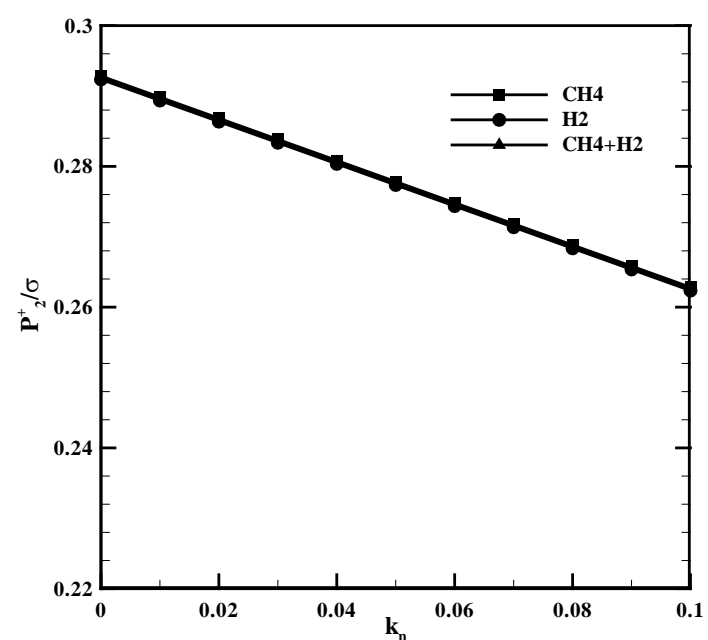

(a)

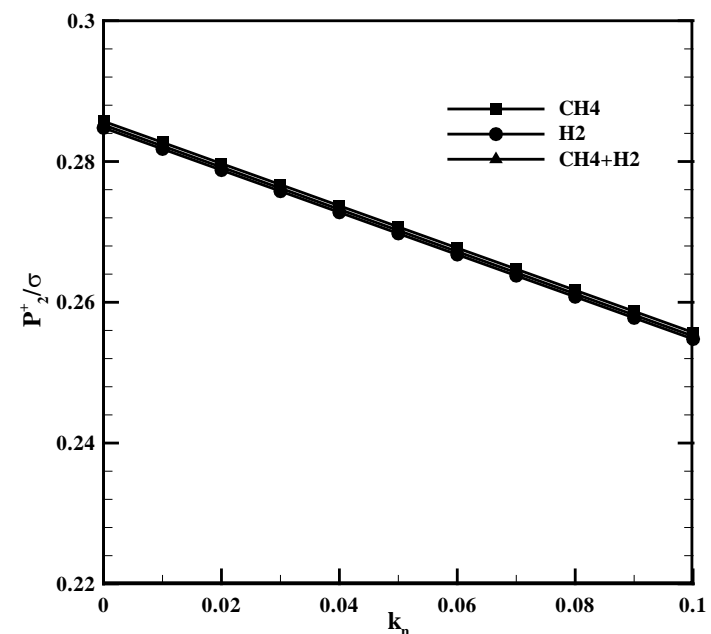

(b)

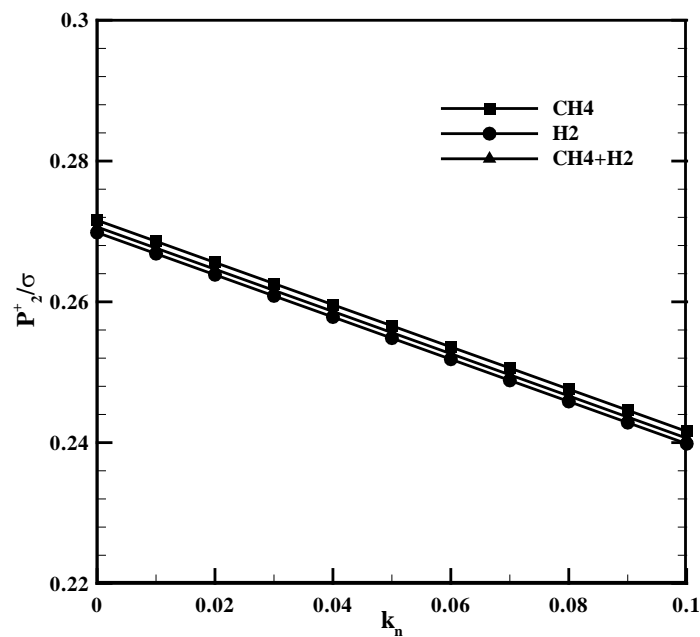

(c)

Fig. 7. The transmitted $\left(\mathrm{P}_{2}^{+}\right)$wave versus $\mathrm{k}_{\mathrm{n}}$ for a supercritical nozzle and the inlet Mach number of (a) 0.025 , (b) 0.05 , (c) 0.1 .

\section{Conclusions}

The transmitted noise emitted from an exit nozzle of a combustor in subcritical and supercritical condition is theoretically investigated. All real nozzles include heat transfer and hydrodynamic decaying mechanisms. Accordingly, the effect of the preceding factors is studied. Further, the effect of adding hydrogen to the hydrocarbon fuel on the emitted noise is considered. The main findings of this work can be summarized as the following.

1) In a nozzle with the incident acoustic wave,

- hydrogen fuel reduces the transmitted noise of a subcritical nozzle, while it increases the noise in the supercritical condition,

- cooling of a nozzle increases the transmitted noise, 
- $\quad$ the transmitted noise decreases by increasing the nozzle inlet Mach number.

2) In a nozzle with the incident entropic wave,

- the transmitted noise is so smaller than those of incident acoustic wave,

- hydrogen remains no considerable effect on the noise,

- transmitted noise is increased with cooling in subcritical condition, while this is mitigated in supercritical condition,

- the transmitted noise decreases by increasing the nozzle inlet Mach number. Further, as this is found by the relations, the main parameters which cause the differences among noise of hot gases are heat capacity and heat capacity ratio. On other words, the physical properties of the gases can change the acoustic responses caused by them.

\section{References}

[1] Brewer G D. Hydrogen Aircraft Technology. CRC Press; 1991.

[2] Turns S R. An Introduction to Combustion: Concepts and Applications. McGrawHill; 1996.

[3] Lieuwen T. Unsteady combustor physics. Cambridge University Press; 2012.

[4] Howe M. Contributions to the theory of aerodynamic sound, with application to excess jet noise and the theory of the flute. Journal of Fluid Mechanics 1975;71:625673.

[5] Ffwocs Williams JE, Howe MS. The generation of sound by density inhomogeneities in low Mach number nozzle flows. Journal of Fluid Mechanics 1975;41:207-232.

[6] Marble FE, Candel SM. Acoustic Disturbances From Gas Non-Uniformities Convected Through a Nozzle. Journal of Sound and Vibration 1977;55(2):225-243.

[7] Cumpsty NA, Marble FE. Core noise from gas turbine exhausts. Journal of Sound and Vibration 1977;54(2):297-309.

[8] Cumpsty NA. Jet Engine Combustion Noise: Pressure, Entropy and Vorticity Perturbations Produced by Unsteady Combustion or Heat Addition. Journal of Sound and Vibration 1979;66(4):527-544.

[9] Bake F, Kings N, Rohle I. Fundamental Mechanism of Entropy Noise in AeroEngines: Experimental Investigation. Journal of Engineering for Gas Turbines and Power 2008;130(1):011202-1 - 011202-6

[10] Bake F, Richter C, Muhlbauer B, Kings N, R“ohle I, Thiele F, Noll B. The Entropy Wave Generator (EWG): A Reference Case on Entropy Noise. Journal of 
Sound and Vibration 2009; 326(3-5):574-598.

[11] Sattelmayer $T$. Influence of the combustor aerodynamics on combustion instabilities from equivalence ratio fluctuations. Journal of Engineering Gas Turbines Power 2003;125:11-20.

[12] Motheau E, Nicoud F, Poinsot T. Mixed acoustic-entropy combustion instabilities in gas turbines. Journal of Fluid Mechanics 2014;749:542-576.

[13] Karimi N, Brear M, Moase W. Acoustic and disturbance energy analysis of a flow with heat communication. Journal of Fluid Mechanics 2008;597:67-89.

[14] Karimi N, Brear M, Moase W. On the interaction of sound with steady heat communicating flows. Journal of Sound and Vibration 2010;329 (22):4705-4718.

[15] Lourier JM, Huber A, Noll, B, Aigner M. Numerical Analysis of Indirect Combustion Noise Generation within a Subsonic Nozzle. AIAA Journal 2014;52(10):2114-2125.

[16] Kido H, Nakahara M, Nakashima K, Hashimoto J. Influence of local flame displacement velocity on turbulent burning velocity. Proceedings of the Combustion Institute 2002;29: 1855-1861.

[17] Lieuwen T, McDonell V, Petersen E, Santavicca DA. Fuel flexibility influences on premixed combustor blowout, flashback, auto-ignition, and stability. Journal of Engineering for Gas Turbines and Power 2008; 130(1): 954-961.

[18] Figura L, Lee JG, Quay BD, Santavicca DA. The effects of fuel composition on flame structure and combustion dynamics in a lean premixed combustor. ASME Turbo Expo: Power for Land, Sea, and Air 2007; 2: 181-187.

[19] Nguyen T A, Mikami M. Effect of hydrogen addition to intake air on combustion noise from a diesel engine. International Journal of Hydrogen Energy 2013; 38: 4153-4162.

[20] Leyko M, Moreau S, Nicoud F, Poinsot T. Numerical and analytical modeling of entropy noise in a supersonic nozzle with a shock. Journal of Sound and Vibration 2011;330:3944-3958

[21] John J E, Theo G K. Gas Dynamics. Pearson Prentice Hall; 2006

[22] Shapiro AH. The Dynamics and Thermodynamics of Compressible Fluid Flow. Vol. 1. New York: The Ronald Press Company; 1953.

[23] Morgans AS, Goh CS, Dahan JA. The dissipation and shear dispersion of entropy waves in combustor thermoacoustics. Journal of Fluid Mechanics 2013;733:R2-1-R2-11. 
[24] Goh CS, Morgans AS. The Influence of Entropy Waves on the Thermoacoustic Stability of a Model Combustor. Combustion Science Technology 2013;185:249-268.

[25] Van Wylen G J, Sonntag R E, Borgnakke C. Fundamentals of Thermodynamics 6th Edition. 6th ed. Wiley: 1986. 